\title{
Case Report on Giant Epithelial Splenic Cyst
}

\author{
Thulasi Vasudevaiah¹, Nayana Priyavadan Bhortakay²
}

${ }^{1}$ Department of General Surgery, Adichunchanagiri Institute of Medical Sciences, Mandya, Karnataka, India. 2Department of General Surgery, JSS Academy of Higher Education and Research, Mysore, Karnataka, India.

\section{PRESENTATION OF CASE}

A 15-year-old female patient came with complaint of pain in the left hypochondriac region from past 2 months, which was dull aching, intermittent, aggravated on taking deep breaths, and relieved at rest. Patient also gave history of early satiety. No history of trauma, vomiting, altered bowel habits, fever, night sweats, and weight loss. The patient denied history of any recent travel. On physical examination, a firm nontender mass of size $20 \times 15 \mathrm{~cm}$ was palpated in the left hypochondriac region extending to the epigastric, umbilical and left lumbar region with medial border at $5 \mathrm{~cm}$ right lateral to the umbilicus and finger insinuation was not possible below the left costal margin. The patient underwent ultrasound abdomen which showed large well defined cystic lesion measuring $20 \times 19 \times 30 \mathrm{~cm}$, volume $5000-5700 \mathrm{cc}$ occupying the left hypochondrium, lumbar, epigastric and umbilical regions with irregular trabeculated wall and internal echoes within. It was seen causing mass effect in the form of posterior displacement of bilateral kidneys, spleen and inferior displacement of bowel loops. Features were suggestive of probable large mesenteric cyst. Computed tomography (CT) of abdomen and pelvis with oral and intravenous contrast was done which showed a large thin-walled abdominal cystic lesion measuring $19 \times 18 \times 22 \mathrm{~cm}$ of volume approximately 3500-4000cc occupying the left hypochondrium, epigastric region, umbilical region, reaching up to the lumbar region. It was seen arising from spleen with thinned out splenic parenchyma along its superior, lateral and inferior aspect (claw sign). Anteriorly it was extending to the anterior abdominal wall and abutting the recti muscles. Mass effect was noted on liver and right kidney with displacement of the organs (Figure 1: a, b).
Corresponding Author: Dr. Nayana Priyavadan Bhortakay, Department of General Surgery, JSS Academy of Higher Education and Research, Mysore, Karnataka, India. E-mail: naya.pb123@gmail.com

DOI: $10.14260 / \mathrm{jemds} / 2022 / 58$

How to Cite This Article:

Vasudevaiah T, Bhortakay NP. Case report on giant epithelial splenic cyst. J Evolution Med Dent Sci 2022;11(01):308-310, DOI: $10.14260 / \mathrm{jemds} / 2022 / 58$

Submission 09-12-2021,

Peer Review 15-12-2021,

Acceptance 09-01-2022,

Published 31-01-2022.

Copyright (c) 2022 Thulasi Vasudevaiah et al. This is an open access article distributed under Creative Commons Attribution License [Attribution 4.0 International (CC BY 4.0)] 


\section{CLINICAL DIAGNOSIS}

Massive splenomegaly

\section{DIFFERENTIAL DIAGNOSIS}

Gastrointestinal tumour of stomach, mesenteric cyst

\section{PATHOLOGICAL DISCUSSION}

Histopathological examination showed gross specimen of the spleen measuring $17 \mathrm{x} 4 \mathrm{x} 4 \mathrm{~cm}$ with splenic cyst measuring $14 \times 10 \times 2 \mathrm{~cm}$. Outer surface of the spleen was unremarkable whereas outer surface of the splenic cyst appeared to be congested with inside surface showing some trabeculations as well as necrotic debris.

Microscopically sections of splenic cyst showed a cystic lesion lined by columnar epithelium and sub epithelial tissue showed areas of collagenisation and granulation tissue consisting of proliferating blood vessels, lymphocytes and neutrophils. Adjacent splenic tissue shows areas of haemorrhage - features of primary splenic cyst (epithelial splenic cyst with secondary infection).

Ca19-9 and CEA of splenic cyst fluid were elevated.
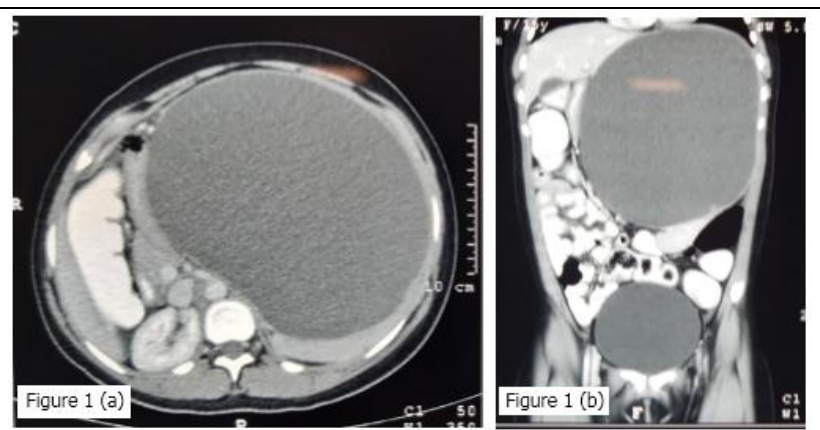

Figure 1. CT Abdomen Showing Large Splenic Cyst (a) Axial View, (b) Coronal View

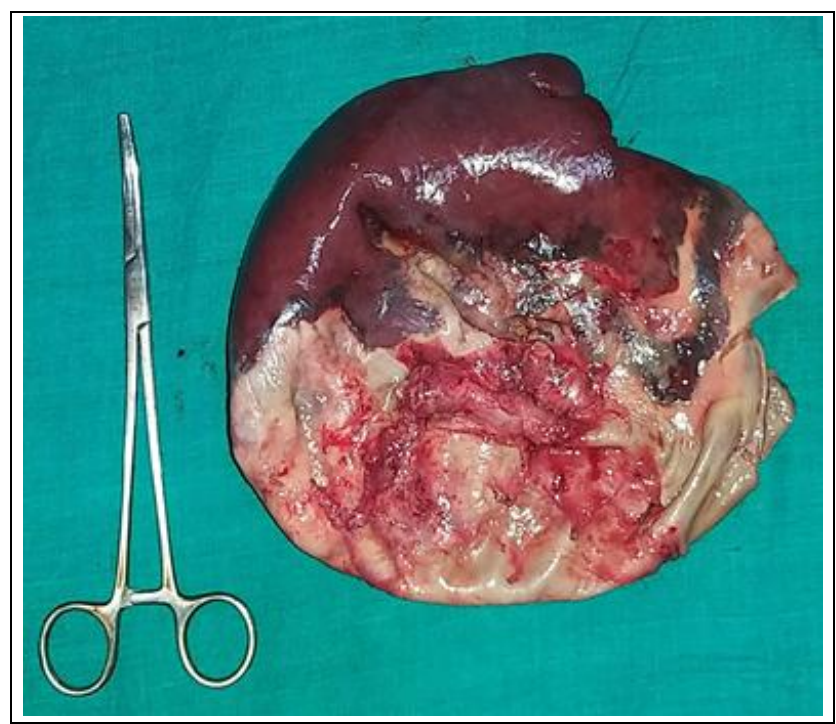

Figure 2. Splenic Cyst Occupying the Entire Spleen Involving the Hilum

\section{DISCUSSION OF MANAGEMENT}

The patient was planned for splenectomy, hence preoperative pneumococcal, Hib and meningococcal vaccines were given 2 weeks prior to the surgery. Intraoperatively a huge splenic cyst was found occupying the whole spleen involving hilum as shown in Figure 2. The cyst was adhering to the left lobe of the liver, left hemidiaphragm, stomach. To prevent spillage of cyst fluid intraabdominal, $16 \mathrm{~F}$ foley catheter was inserted into the cyst and was sutured to its wall to allow drainage of cyst fluid. After decompression of the cyst, total splenectomy was performed. Patient recovered well and was discharged on POD 3 after drain removal.

Splenic cysts are rare findings (incidence is 0.75 per 100,000). Nowadays, splenic cysts are known as rare clinical condition. According to the presence or absence of cellular epithelial lining, these cysts are classified into primary (true) and secondary (false) cysts. Primary cysts are subdivided into parasitic (60\%) and non-parasitic cyst due to their aetiology. Non parasitic cysts are commonly congenital. ${ }^{1}$ Amongst parasitic splenic cysts most cases result from by Echinococcus granulosus, a form called splenic hydatid disease. ${ }^{2}$ On the other hand, secondary splenic cysts include $75 \%$ of nonparasitic types and may spread after blunt abdominal trauma. ${ }^{3}$ True cysts account for $10 \%$ of all the splenic cysts.

Primary splenic cysts are usually asymptomatic but may present with left upper quadrant pain or mass in left hypochondrium. The diagnosis of true splenic cysts is commonly made in the $2^{\text {nd }}$ and $3^{\text {rd }}$ decades of life. ${ }^{4}$ True cysts are characterized by a squamous epithelial lining, and many are considered congenital. These epithelial cells are often positive for CA 19-9 and CEA by immunochemistry, and patients with epidermoid cysts of the spleen may have elevated serum levels of one or both of these tumourassociated antigens. ${ }^{5}$ Despite the presence of these tumour markers, these cysts are benign and apparently do not have malignant potential greater than any other native tissue.

Splenic cysts are usually asymptomatic and are incidental findings on ultrasound. Contrast enhanced CT of abdomen can be done to confirm the diagnosis.

Treatment of parasitic splenic cysts differs from that for non-parasitic splenic cysts. Treatment of non-parasitic cyst depends upon the size of the cyst and related symptoms. Asymptomatic cysts that are $<5 \mathrm{~cm}$ in diameter, particularly non-parasitic ones, are best followed conservatively. ${ }^{6}$ For spontaneously resolving splenic cysts, serial monitoring with $\mathrm{CT}$ is required. If size of splenic cyst is reducing, conservative treatment can be continued. If progress in size is noted, patient can be advised for surgical treatment. Cysts $>5 \mathrm{~cm}$ are susceptible to haemorrhage, rupture, and infection and should be managed surgically, even when asymptomatic. ${ }^{7}$ Surgical options include percutaneous aspiration, marsupialization of cyst, partial or total. These procedures can be done by laparoscopy or open techniques.

In 1985, Salky and associates reported the first laparoscopic treatment of a splenic cyst by creating a cystperitoneal window. ${ }^{8}$ The cyst was decompressed with an aspiration needle, and a $5-\mathrm{mm}$ scissors instrument with cautery was used to make a $3-\mathrm{cm}$ window in the cyst wall. Percutaneous aspiration of the cyst fluid is associated with high recurrence rates. The most common technique for marsupialization includes removing a large portion of the cyst 
wall without dividing splenic parenchyma. This can be attempted for more superficially located splenic cysts. Laparoscopic excision of nonparasitic splenic cysts in children is associated with a high recurrence rate and may be an insufficient treatment. ${ }^{9}$ Partial splenectomy can be done for cysts located in the poles as an attempt to preserve splenic tissue. Total splenectomy is an option in children for the treatment of splenic cysts larger than $10 \mathrm{~cm}$ as this eradicates potential rupture with secondary development of infection and hemoperitoneum. ${ }^{10}$

\section{FINAL DIAGNOSIS}

Giant primary epithelial splenic cyst.

Financial or other competing interests: None.

Disclosure forms provided by the authors are available with the full text of this article at jemds.com.

\section{REFERENCES}

[1] Golmohammadzadeh H, Maddah G, Hojjati YS, et al. Splenic cysts: analysis of 16 cases. Caspian J Intern Med 2016;7(3):217-21.
[2] Vezakis A, Dellaportas D, Polymeneas G, et al. Two cases of primary splenic hydatid cyst in Greece. Korean J Parasitol 2012;50(2):147-50.

[3] Karfis EA, Roustanis E, Tsimoyiannis EC. Surgical management of nonparasitic splenic cysts. JSLS 2009;13(2):207-12.

[4] Cowles RA, Yahanda AM. Epidermoid cyst of the spleen. Am J Surg 2000;180(3):227.

[5] Yigitbasi R, Karabicak I, Aydogan F, et al. Benign splenic epithelial cyst accompanied by elevated Ca 19-9 level: a case report. Mt Sinai J Med 2006;73(6):871-3.

[6] Rana APS, Khichy S, Kaur H, et al. Large splenic cyst: a rare presentation. Cureus 2021;13(4):e14435.

[7] Chin EH, Shapiro R, Hazzan D, et al. A ten-year experience with laparoscopic treatment of splenic cysts. JSLS 2007;11(1):20-3.

[8] Salky B. Zimmerman M, Bauer J, et al. Splenic cyst-definitive treatment by laparoscopy. Gastrointest Endosc 1985;31(3):213-5.

[9] Fisher JC, Gurung B, Cowles RA. Recurrence after laparoscopic excision of nonparasitic splenic cysts. J Pediatr Surg 2008;43(9):1644-8.

[10] Estavillo PM, Luna MJ, Cuevas OVJ, et al. Treatment of splenic cyst greater than $10 \mathrm{~cm}$ by total laparoscopic splenectomy. A case report. Rev Mex Cir Endoscop 2016;17(1):34-7. 